\title{
Presentation of calcinosis cutis 35 years after silicone nasal implant reconstruction
}

\author{
Luis A Antezana 다, ${ }^{1}$ Anita T Mohan, ${ }^{2}$ Uldis Bite ${ }^{2}$
}

${ }^{1}$ Mayo Clinic Alix School of Medicine, Mayo Clinic Rochester, Rochester, Minnesota, USA ${ }^{2}$ Department of Surgery, Division of Plastic and Reconstructive Surgery, Mayo Clinic, Rochester, Minnesota, USA

\section{Correspondence to \\ Dr Uldis Bite; \\ bite.uldis@mayo.edu}

Accepted 15 January 2021

\section{DESCRIPTION}

A 63-year-old female patient with a history of congenital saddle nose deformity and two previous reconstructive rhinoplasties presented with a painful nodule, progressive swelling and mild redness on the nasal dorsum and right-sided nasal obstruction. The last of her two closed rhinoplasties was performed over 30 years ago, the operative details of which were not available. However, procedures included possible use of autografts from the nose and suspected allograft. Only recently did she develop

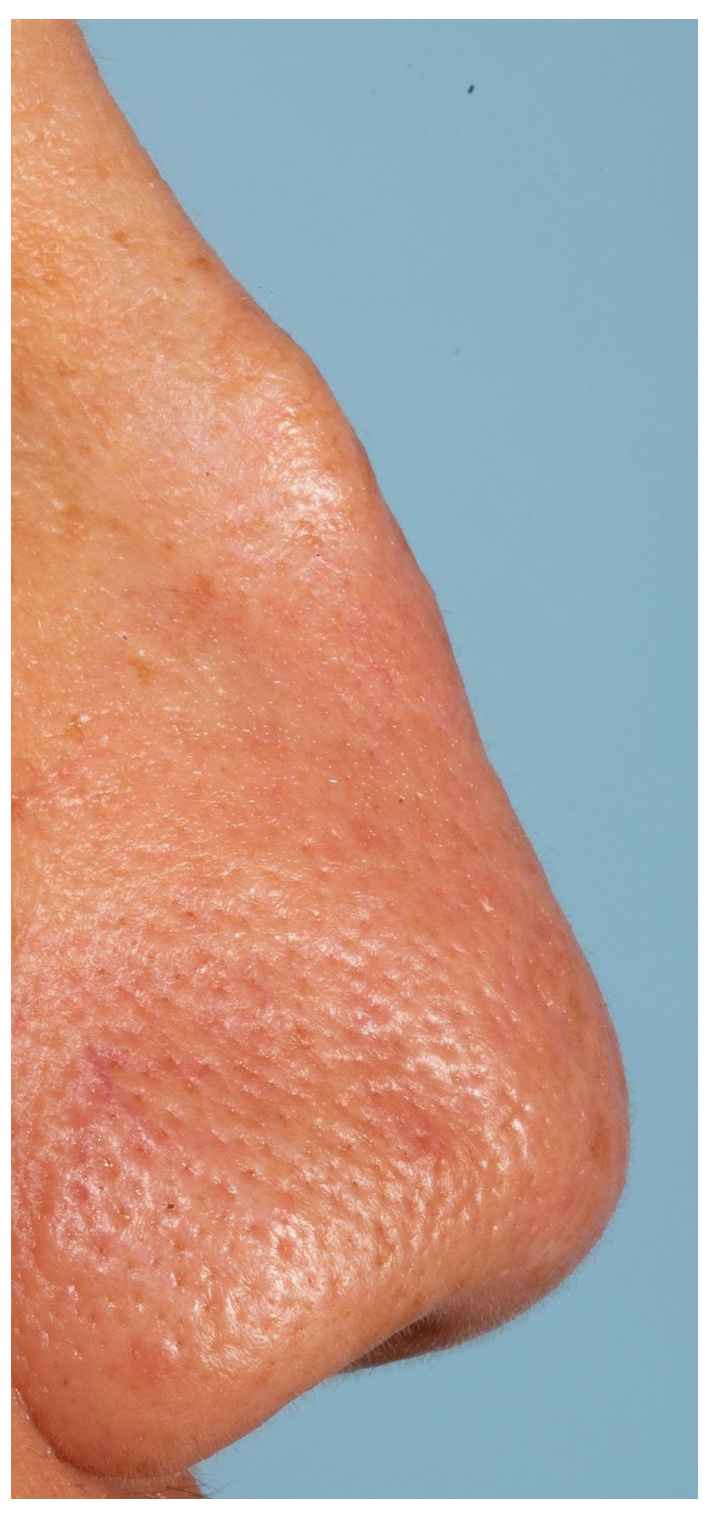

Figure 1 Preoperative lateral photograph depicting a $5 \mathrm{~mm}$ painful nodule situated directly on the nasal dorsum.

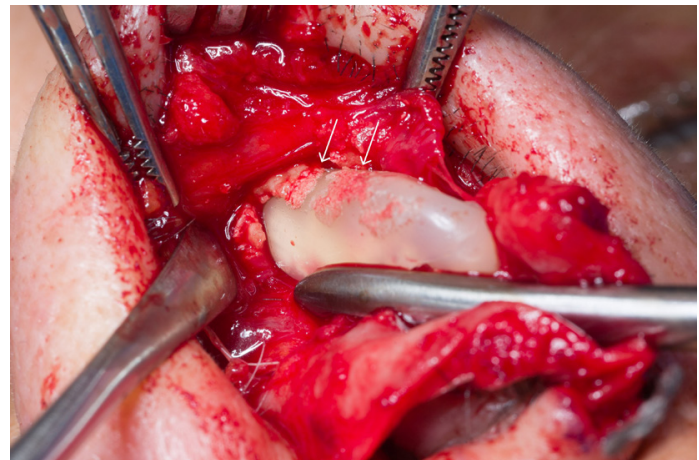

Figure 2 Intraoperative photograph demonstrating capsular contracture and calcification of an L-shaped silicone nasal implant. Arrows show areas of extensive calcification.

isolated tenderness over the nasal bones. Physical examination revealed a $5 \mathrm{~mm}$ palpable tender mass attached to a mobile graft encompassing the entire nasal dorsum alongside right-sided internal valve collapse (figure 1). A preoperative CT scan demonstrated a calcified structure on the nasal dorsum suggesting a previous reconstruction allograft. The assessment and plan included removal of existing graft and complex revision open septorhinoplasty and nasal reconstruction with rib cartilage. Intraoperative findings were surprising and demonstrated the presence of widespread calcification in the skin associated with an L-shaped silicone implant and extensive capsular contracture (figure 2). Histopathological examination illustrated deposits of calcified material in the subcutaneous tissue and dermis with peripheral fibrosis. She underwent a total capsulectomy and implant removal followed by autologous reconstruction using her rib cartilage to recreate the L-strut of the nasal septum. Diced rib cartilage wrapped in rectus fascia corrected her original severe saddle nose deformity, and further cartilage grafts alleviated her nasal obstruction. Her postoperative course was uneventful.

Calcinosis cutis is characterised by deposition of insoluble calcium in the skin and subcutaneous tissues. Dystrophic and metastatic classification types account for the majority of cases. Dystrophic is identified by tissue damage with normal serum phosphate and calcium, whereas metastatic presents with abnormal calcium and/or phosphate metabolism. Remaining cases are classified as iatrogenicinadvertent calcium deposition from medical intervention-or, if cause is unidentifiable, idiopathic. ${ }^{1}$ Traditionally, clinicians used a fifth domain, calciphylaxis, now a misnomer, for small vessel 
calcification seen in chronic renal failure. Calcific uraemic arteriolopathy should be more readily used. ${ }^{2}$ Lesions on the nose are rare-typically presenting as firm masses on the nasal dorsum, not typically associated with pain. Further consideration should aim to rule out foreign body, malignancy or calcinosis resulting from collagen disorders (ie, dystrophic calcification seen in dermatomyositis and systemic sclerosis). We present a case of calcinosis cutis associated with a silicone implant. Although silicone exhibits low biological reactivity, severe calcification on the implant's surface can be reported many years after implantation. ${ }^{3}$

The mechanism for implant calcification remains unclear. However, silicone compared with non-silicone implants are at greater risk of calcifying. ${ }^{4}$ Foreign body and inflammatory reactions-likely from long-term mechanical stress-may play a role in calcium phosphate deposition. ${ }^{5}$ These reactions tend to lower

Learning points

Calcified nodules in the skin might be due to a local process or symptom of systemic disease and require a thorough history and relevant work-up to identify an underlying aetiology.

- Silicone implants in the nose can also develop capsular contracture that can lead to persistent pain symptoms similar to that experienced with breast implants (Baker grade IV). tissue $\mathrm{pH}$ to levels suitable for calcium phosphate precipitation. Our case was positive for erythema and swelling indicative of inflammation. Similar to calcified capsules formed around breast implants, the capsule formed around the silicone implant led to contracture, distortion and pain over time in our patient.

Contributors ATM and UB and LAA contributed to the writing, revision and submission of this manuscript.

Funding The authors have not declared a specific grant for this research from any funding agency in the public, commercial or not-for-profit sectors.

Competing interests None declared.

Patient consent for publication Obtained.

Provenance and peer review Not commissioned; externally peer reviewed.

\section{ORCID iD}

Luis A Antezana http://orcid.org/0000-0003-1575-3593

\section{REFERENCES}

1 Niebel D, Poortinga S, Wenzel J. Osteoma Cutis and Calcinosis Cutis: "Similar but Different". J Clin Aesthet Dermatol 2020;13:28-31.

2 Llach F. Calcific uremic arteriolopathy (Calciphylaxis): an evolving entity? Am J Kidney Dis 1998;32:514-8.

3 Little G, Baker JL. Results of closed compression capsulotomy for treatment of contracted breast implant capsules. Plast Reconstr Surg 1980;65:30-3.

4 Jung DH, Kim BR, Choi JY, et al. Gross and pathologic analysis of long-term silicone implants inserted into the human body for augmentation rhinoplasty: 221 revision cases. Plast Reconstr Surg 2007;120:1997-2003.

5 Kossovsky N, Freiman CJ. Silicone breast implant pathology. clinical data and immunologic consequences. Arch Pathol Lab Med 1994;118:686-93.

Copyright 2021 BMJ Publishing Group. All rights reserved. For permission to reuse any of this content visit https://www.bmj.com/company/products-services/rights-and-licensing/permissions/

BMJ Case Report Fellows may re-use this article for personal use and teaching without any further permission.

Become a Fellow of BMJ Case Reports today and you can:

- Submit as many cases as you like

- Enjoy fast sympathetic peer review and rapid publication of accepted articles

- Access all the published articles

- Re-use any of the published material for personal use and teaching without further permission

Customer Service

If you have any further queries about your subscription, please contact our customer services team on +44 (0) 2071111105 or via email at support@bmj.com.

Visit casereports.bmj.com for more articles like this and to become a Fellow 